\title{
Emotional Intelligence and Its Relationship to Academic Performance among Saudi EFL Undergraduates
}

\author{
Wafa Ismail Saud ${ }^{1}$ \\ ${ }^{1}$ Department of English, Faculty of Languages and Translation, King Khalid University, Abha, Saudi Arabia. \\ Correspondence: Dr. Wafa Ismail Saud, P. O. Box No. 11979, Post Code 61321, Abha, Saudi Arabia. E-mail: \\ wafasaud@hotmail.com
}

Received: September 2, 2019

Accepted: October 19, 2019

Online Published: October 23, 2019

doi:10.5430/ijhe.v8n6p222

URL: https://doi.org/10.5430/ijhe.v8n6p222

\begin{abstract}
The purpose of the present study was to describe the emotional intelligence level of Saudi EFL undergraduate students, as well as to examine the effect of emotional intelligence on success in foreign language learning. A total of 80 Saudi undergraduate students from the English Department at King Khalid University participated in this study. Data was collected by means of Schutte Self Report Emotional Intelligence Test (SSEIT), and by an English achievement test. SSEIT questionnaire data was matched with the students' academic scores in the English language achievement test, and was analysed using SPSS. The findings indicated that Saudi EFL students scored a high level of emotional intelligence. The most popular intelligence subscales they used were "Utilization of Emotion" followed by "Management of Others Emotion" and "Management of Self Emotion" and finally, "Perception of Emotion". Another finding indicated that two of the four subscales, "Utilization of Emotion and "Management of Others Emotion" were significantly associated with their English achievement level. The implications of the value of emotional intelligence in fostering academic achievement were considerable for both EFL teachers and academic policymakers.
\end{abstract}

Keywords: achievement level, emotional intelligence, management of emotion, perception of emotion, Saudi undergraduate students, utilization of emotion

\section{Introduction}

The field of teaching English as a second or foreign language has entered a new realm in the process of improving education. Besides the focus on the cognitive aspects of the students, there is a demand to explore their affective domains which influence language learning. Emotional intelligence refers to the ability to recognise, understand and manage one's own emotions, and that of others, and use them to achieve success in life. Emotional intelligence is thought to have a high impact on many aspects of learners' life, including their academic achievement level. There is a growing interest in studying students' emotional intelligence as a factor that may contribute to their educational success (Elias, Arnold \& Hussey, 2003). Goleman (1995) declares the superiority of emotional intelligence over intelligent Quotient (IQ) in predicting success. Besides, Goleman (2001) describes the power of emotional intelligence in facilitating language learning by serving the internal mechanisms and external environment. Similarly, Imai, (2005) argues that emotions play a great role in language learning as students have to overcome the challenges they face during the process of learning. Likewise, Al-Asmari (2014) explains how emotional intelligence is essential in education, and how it is associated with academic success.

\subsection{Statement of the Problem}

In educational systems, most of the attention is given to students' mental and memory aspects. Little attention is paid to the relationship between emotions and learning. Emotional intelligence needs to be addressed when dealing with the domain of language learning. Affective factors such as having a high level of emotional intelligence help students attain a high degree of success in second or foreign language learning (Fahimand Pishghadam (2007). Recently, several studies started to examine the association of emotional intelligence and academic achievement level among students, but they failed to achieve consistent results, that raised a need for further study. Therefore, the present study aimed to explore the emotional intelligence level of Saudi EFL undergraduate students and investigate its role in foreign language learning. It would be insightful to know how to assist emotionally intelligent students when needed. It is also important to examine the influence of students' emotional intelligence on their academic performance to 
improve the quality of their education.

\subsection{Objectives}

The present study aims to identify the emotional intelligence level of Saudi undergraduate students, and to determine whether their achievement in the English language varies according to their emotional intelligence level.

The study objectives are as follows:

1. To identify the emotional intelligence level among Saudi EFL undergraduate students.

2. To examine whether the English language achievement of Saudi undergraduate students varies according to their level of emotional intelligence.

Specifically, the following major research questions are addressed.

1. What is the emotional intelligence level of Saudi undergraduate students?

2. Does the emotional intelligence level of Saudi EFL undergraduate students influence their achievement level?

\subsection{Significance of the Study}

Low, Lomax, Jackson and Nelson (2004) present a correlation between emotional knowledge, skills, and intelligence with achievement, career, leadership and personal well-being. Similarly, Wicks, Nakisher and Grimm (2018) report that emotional skills can improve academic achievement by 11 percentile points, and decrease aggression and behaviour problems by 9 percent. There is a need for students to control their emotions and enhance their emotional intelligence competencies to achieve academic and career excellence. Students have to learn how to handle appropriate emotions at specific times and places. Similarly, Fahim and Pishghadam (2007) stress the association of emotional intelligence level and academic success. This study is an attempt to shed some light on the relationship between emotional intelligence and academic success among Saudi undergraduate students. Results could be used by professors and academics to include the concept of emotional intelligence in their students' curriculum, and in their language classrooms, to help them cope better with educational and social pressures, and to achieve success.

\section{Theoretical Framework and Empirical Studies}

\subsection{The History of Emotional Intelligence}

Mehta and Singh (2013) shed some light on the history of the concept of "emotional intelligence". The origin of the concept can be traced back to "social intelligence" that was introduced by Edward Thorndike in the 1930s who described "social intelligence" as the capacity to communicate successfully with people. In the 1950s Abraham Maslow, a humanistic psychologist, focused on the field of building emotional strength. Later, in 1975, Howard Gardner developed the term "multiple intelligences", in his publication "The Shattered Mind" that includes six types of intelligences, they are: linguistic intelligences, logical-mathematical intelligence, musical intelligence, bodily-kinesthetic intelligence, intrapersonal intelligence, and interpersonal intelligence. The first published use of the term "emotional quotient" was by Keith Beasley in 1987. Three years later in 1990, an article entitled "Emotional Intelligence" by Peter Salovey and John Mayer was published. Finally, in 1995, Daniel Goleman published a book called "Emotional Intelligence: Why it can matter more than IQ", and since then the concept of emotional intelligence was popularized.

\subsection{The Concept of Emotional Intelligence}

The term emotional intelligence is defined in a variety of ways. The definitions overlap, but there are also differences. It is a subset of social intelligence, and it refers to the ability to regulate and control one's own emotions, and that of others, and to differentiate between them (Salovey \& Mayer, 1990). Later, some other personality attributes were added to the definition, such as self-confidence, conscientiousness, and achievement motive (Goleman, 1995; Goleman, 1998). Another development in the definition was provided by Mayer and Salovey (1997) which suggests an emotional intelligence model that consists of four abilities: perceiving emotions, using emotions, comprehending emotions and managing emotions. Later, Mayer, Caruso \& Salovey (1999) define emotional intelligence as a set of mental abilities. Ciarrochi, Chan \& Caputi (2000) added emotional intelligence is a combination of intelligence and emotion. Furthermore, Bar-On \& Parker (2000) extend the meaning of emotional intelligence to include emotional, personal, and social abilities that have a great impact on a person's overall ability. It helps people lead their social and personal life effectively and manage pressures and difficulties. Zeidner, Roberts \& Matthews (2002) point out that emotional intelligence consists of appraisal, expression, utilization, and regulation of one's own emotions and the emotions of others. Mayer, Salovey and Caruso (2004) argue that emotional intelligence is the ability to reason and to use emotion to assist thought. Other researchers differentiated between emotional intelligence and social 
competence. Cherniss (2010) described emotional intelligence as the ability to perceive emotions and regulate them, while social competence means the aptitude of emotional intelligence. In short, emotional intelligence was viewed as an ability, a skill, a competence, and as a personality trait (Wicks, Nakisher and Grimm, 2018).

\subsection{Teaching Emotional Intelligence}

As emotional intelligence helps students excel in their academic success, it can help teachers as well to be effective and excel in their profession. Kremenitzer and Miller (2008) highlight the crucial role of teachers' emotions in every aspect of the teaching-learning process. They state that teachers' emotional competence is vital for their effectiveness, and influences their behavior, cognition, and motivation. Research has shown that emotional intelligence can be enhanced by using a variety of different methods.

One example is Bar-On (1997) who argues that emotional intelligence can be improved with training, programming and therapy.

Another example is Elhaj (2015) who suggests a framework to build emotional intelligence in schools. It focuses on four areas. The first one is the emotional intelligence in the curriculum. Students' emotional needs should be addressed by focusing on aural, visual, physical mathematics space, and interpersonal intelligences. The second area is emotional intelligence and school and classroom environment. The conditions of the classroom should encourage students' management of emotions, and it should encourage them in making sound decisions. The third area is emotional intelligence and student's psychological health. Teachers have to use psychological techniques to motivate their students to learn, and use it to support them. The fourth area is the school-family partnership. Schools can communicate with families to provide them with some parenting skills, and to share opinions about students' needs and progress.

Finally, the last example is the findings of the study of Dacre and Qualter (2019) who provide evidence of improving the emotional intelligence of university students, through emotional intelligence teaching intervention.

\section{Empirical Studies}

There is a growing body of research that focuses on the importance of feelings on leaning, such as Mayer, Salovey \& Caruso, 2000; Saklofske, Austin \& Minski, 2003; and Motallebzadeh, 2009. Research on emotional intelligence and second or foreign language learning states that emotional intelligence can affect language learning either positively or negatively. Among the several studies was a study by Newsome, Day, \& Catano (2000) who investigated the relationship of emotional intelligence and achievement level. The EQ-i emotional intelligence test was used. The findings indicated that there was a significant relationship between cognitive ability and personality, and academic achievement.

Similarly, Petrides, Frederickson and Furham (2004) examined the association of emotional intelligence and academic achievement at a British secondary school on a sample of 650 students. The study concluded that emotional intelligence was significantly related to scholastic achievement, and especially for disadvantaged adolescents.

Qualter, Whiteley, Morely \& Dudiac (2009) investigated the effect of the level of emotional intelligence on academic success at university. The participants were 465 undergraduate students, chosen from an Australian university. Results showed that students with higher emotional intelligence scores had higher academic performance than students with lower scores.

On the contrary, Kashani, Azimi \& Vaziri (2012) investigated the use of emotional intelligence and its relationship to academic achievement. A total of 100 students from Islamic Azad University participated in the study. The tool used was the emotional intelligence questionnaires designed by Bradberry \& Greaves (2003). The results indicated that there was no relationship between emotional intelligence and academic achievement.

Others such as Al-Asmari (2014) investigated the relationship between emotional intelligence and academic achievement. The sample consisted of 100 males and 100 females. EQ-I scale and an English language test were used to collect the data. The results reported that emotional intelligence had a positive correlation to academic achievement for females.

On the contrast, Al-Ghamdi (2014) conducted a study to examine the effect of gender and academic success on emotional intelligence. Schutte self-report emotional intelligence questionnaire was used on a sample of 191 undergraduate students, from a university in Al-Baha province, Saudi Arabia. Results revealed that there is no statistically significant relationship between emotional intelligence and the variables academic performance and gender. 
Al-Shakifi (2015) aimed to explore the emotional intelligence level and the practice of mind habits of undergraduate students, and examine the relationship of emotional intelligence to academic achievement. A total of 60 male, and 70 female students, at Al-Qanfada University College, Saudi Arabia, participated in the study. Bar-On's (2000) emotional intelligence scale, and Roger's (2000) Mind Habits scale, were used. The findings reported a high level of emotional intelligence and a moderate practice level of mind habits. Another finding revealed that there was a correlation between mind habits, emotional intelligence, and achievement level.

Another study by Elhaj (2015) investigated the effectiveness of emotional intelligence on student's English language achievement. 330 school students in the Khartoum locality participated in the study. The Bar-On Emotional Quotient Test was used to collect the data. The findings revealed that there was a significant positive relationship between Emotional Intelligence and the achievement level of English language students.

$\mathrm{Oz}$ (2015) conducted a study at a university in Ankara, Turkey to investigate the effect of emotional intelligence on communication in English. The sample was 165 Turkish EFL students. Two scales were used as instruments to collect the data; they were the Emotional Intelligence, and the Willingness to Communicate. The results revealed that the students had a high level of emotional intelligence and a moderately-high level of willingness to communicate in a second language. This means that students' emotional intelligence helps them achieve a satisfactory level of second language communication.

Sahinidis, Kallivokas, Antonatou, and Sdrolias (2016) examined the influence of emotional intelligence on academic performance. The participants were 648 university students. Trait Emotional Intelligence Questionnaire was used in the study. The academic performance of the students was assessed by using the grade point average (GPA). The findings reported no influence of emotional intelligence on academic performance.

Shuib, Ishak, Amat \& Ahmad (2018) investigated the relationship between emotional intelligence and academic achievement. The participants were 918 primary school students. The tool used was the Malaysian Emotional Quotient Inventory-Children (MEQI-C). The findings revealed that academic achievement was strongly associated with six variants. They are self-confidence, self-motivation, self-regulation, self-awareness, spirituality and empathy.

\section{Methodology}

\subsection{Research Design}

The questions of the research were answered by conducting quantitative research. Numeral data was quantified to describe the emotional intelligence level of Saudi EFL undergraduates. First, descriptive statistical procedures were employed for data analysis, such as means and standard deviations. Upon getting the means from the descriptive statistical procedures, they were interpreted accordingly; the mean scores that fell between 1.0 and 2.4 were identified as low-frequency use, 2.5 and 3.4 as medium-frequency use, and that which fell between 3.5 and 5.0 were identified as high-frequency use.

Second, comparative statistics using Analysis of Variance (ANOVA), and One-Sample Test, were used to investigate the differences in the means of emotional intelligence, with regard to English achievement level. The independent variable was the students' level of emotional intelligence, and the dependent variable was the student's grades in the academic achievement test.

\subsection{Participants}

A total of $80 \mathrm{EFL}$ undergraduate students participated in the current study. They were chosen randomly from King Khalid University to represent Saudi EFL undergraduate students. They were all in their fourth year in the English department. Their ages ranged between 22 and 26 years.

\subsection{Instruments}

Researchers designed several instruments to measure emotional intelligence based on some theoretical conceptualizations. The Emotional Intelligence scale of Schutte et al.'s (2009) and the students' achievement test results, were the main data collection tools of the study. The emotional intelligence scale of Schutte et al.'s (2009) was widely used in emotional intelligence studies (Alston, 2009). It is a self-report inventory that considers emotional intelligence as competence in expression, perception, regulation, and utilization of emotions in self and others. It contains 33 items which are divided into four subscales: Perception of Emotion, Managing One's Own Emotions, Managing Other's Emotions and Utilizing Emotions. It has a Likert Scale format, where students are asked to report how often they use each of the 33 items on a scale of one to five. The choices are: strongly disagree, disagree, neither disagree nor agree, agree and strongly agree. All students were chosen from level eight. In order to measure their academic performance, an achievement test was designed, administered and marked by the researcher. 
It was checked for validity by an expert in the field of applied linguistics. All the students took the exam at the same time and under the same conditions. The data of the questionnaire was matched with the students' scores in the achievement test.

\section{Results}

In the analysis of the data, SPSS (Statistical Package for Social Sciences) was used. The descriptive statistics of means and standard deviations were presented for all scales and subscales of the questionnaires. One-Sample Test analysis and One-Way ANOVA were used in order to examine the influence of emotional intelligence on achievement level.

This section provides a holistic description of the emotional intelligence levels of the students; besides, it explores the influence of emotional intelligence on achievement level. Data from both the questionnaire, and from the achievement test, were matched, recorded, and analysed quantitively by the researcher. The results of the study will provide answers to the following research questions:

\subsection{What is the Emotional Intelligence Level of Saudi Undergraduate Students?}

In terms of overall level, analysis of the data obtained from the emotional intelligence questionnaire of 80 Saudi EFL students, using descriptive statistics, indicated that the overall use of emotional intelligence was high, with a mean and standard deviation of $3.53(0.47)$.

With regard to category level, the emotional intelligence scale is divided into four categories as illustrated in table 1. Each category represents a group of items. These categories are called subscales. In the analysis of the emotional intelligence subscales, the findings indicated that there were some subscales that were used more frequently than others. Table 1 shows the mean score and ranking for each subscale used by Saudi EFL students

Table 1. Mean Score, Standard Deviation and Rank of Emotional Subscales

\begin{tabular}{ccccc}
\hline Emotional Subscales & $N$ & Mean & $\begin{array}{c}\text { Standard } \\
\text { Deviation }\end{array}$ & Rank \\
\hline Utilization of Emotion & 80 & 3.7354 & .65961 & 1 \\
Management of Others Emotion & 80 & 3.6109 & .62039 & 2 \\
Management of Self Emotion & 80 & 3.5639 & .50587 & 3 \\
Perception of Emotion & 80 & 3.3063 & .53471 & 4
\end{tabular}

Table 1 shows that Saudi EFL students used all the subscales at a high level, except for the "Perception of Emotion" subscales, which recorded a medium level. Thus, Saudi EFL students can utilize their emotions well; they can manage their own emotions, and that of others as well; they had a medium perception of emotion.

Another analysis using the One-Sample Test reported that there were significant differences in the distribution of students' scores for the four subscales of emotional intelligence, as shown in Table 2.

Table 2. Significant Variation in The Use of Schutter's Self-Report Emotional Subscales

\begin{tabular}{|c|c|c|c|c|c|c|}
\hline & \multicolumn{6}{|c|}{ One-Sample Test } \\
\hline & \multicolumn{6}{|c|}{ Test Value $=0$} \\
\hline & \multirow[t]{2}{*}{$t$} & \multirow[t]{2}{*}{$d f$} & \multirow[t]{2}{*}{ Sig. (2-tailed) } & \multirow[t]{2}{*}{$\begin{array}{c}\text { Mean } \\
\text { Difference }\end{array}$} & \multicolumn{2}{|c|}{$\begin{array}{l}\text { 95\% Confidence } \\
\text { Interval of the } \\
\text { Difference }\end{array}$} \\
\hline & & & & & Lower & Upper \\
\hline Management of Others Emotion & 52.059 & 79 & .000 & 3.61094 & 3.4729 & 3.7490 \\
\hline Management of Self Emotion & 63.013 & 79 & .000 & 3.56389 & 3.4513 & 3.6765 \\
\hline Perception of Emotion & 55.305 & 79 & .000 & 3.30625 & 3.1873 & 3.4252 \\
\hline Utilization of Emotion & 50.652 & 79 & .000 & 3.73542 & 3.5886 & 3.8822 \\
\hline
\end{tabular}

Table 2 above shows that there are significant differences in the use of emotional intelligence subscales by Saudi EFL undergraduate students. The data obtained indicated that they had the ability to utilize their emotions most frequently, followed by managing others' emotions, then by managing self emotions, and the least frequent one was the perception of emotions. 
Among the 6 items used to show that students' utilization of their emotions in dealing with others were "When I am in a positive mood, I am able to come up with new ideas" scored (4.25), followed by, "When I am in a positive mood, solving problems is easy for me" (3.76), then by, "When my mood changes, I see new possibilities" (3.73), next, "Some of the major events of my life have led to re-evaluating what is important and not important" (3.58), then, "Emotions are one of the things that make any life worth living" (3.56), and the least frequently used one was "When I feel a change in emotions, I tend to come up with new ideas" (3.54).

Among the 8 items that were used by the students to manage others' emotions were "I help other people feel better when they are down" (4.13), followed by "I present myself in a way that makes a good impression on others" (3.79), then, "I compliment others when they have done something well", and "When another person tells me about an important event in his or her life, I almost feel as though I had experienced this event myself" both scored (3.73), Next, "Other people find it easy to confide in me "(3.58). On the other hand, "I like to share my emotions with others" (3.05), was used least often.

Among the 9 items that were used by the students to manage their own emotions were "I use good moods to help myself keep trying in the face of obstacles" (4.04), followed by "I expect that I will do well on most things I try" (3.86), then, "When I am faced with obstacles, I remember times I faced similar obstacles and overcame them", and "I seek out activities that make me happy", both scored (3.84), next, "I expect good things to happen "(3.65), then, "When I experience a positive emotion, I know how to make it last, (3.60), "I motivate myself by imagining a good outcome to tasks I take on, (3.50), and the least items used was "I have control over my emotions" (3.21) and "When I am faced with a challenge, I give up because I believe I will fail" (2.54).

Among the 10 items that are listed under the Perception of Emotions were "I can tell how people feel by listening to the tone of their voices" (3.73), followed by, "I am aware of my emotions as I experience them" (3.63), then "I easily recognize my emotions as I experience them" (3.56), then, "I know what other people feel just by looking at them" (3.53). Finally, the least frequently used items were, "It is difficult for me to understand why people feel the way they do" (2.84), and "I find it hard to understand the non-verbal messages of other people" (2.53).

\subsection{Does the Emotional Level of Saudi EFL Undergraduate Students Influence Their Achievement Level?}

Data reported that there is some variation in the use of emotional intelligence with regard to the achievement test. Table 3 summarizes the differences in the use of emotional intelligence subscales and students' scores in the achievement test.

Table 3. Mean Score and Standard Deviation of the Emotional Subscales and in Relation to Achievement Level

\begin{tabular}{|c|c|c|c|c|c|}
\hline \multicolumn{2}{|c|}{ Score } & Others & Self & Perception & Utilization \\
\hline \multirow{3}{*}{ Fail } & Mean & 3.2813 & 3.4167 & 3.2000 & 3.5417 \\
\hline & $\mathrm{N}$ & 4 & 4 & 4 & 4 \\
\hline & Std. Deviation & .23662 & .39933 & .67823 & .64370 \\
\hline \multirow{3}{*}{ Fair } & Mean & 3.2670 & 3.3333 & 3.1909 & 3.4015 \\
\hline & $\mathrm{N}$ & 22 & 22 & 22 & 22 \\
\hline & Std. Deviation & .68280 & .67368 & .59834 & .77265 \\
\hline \multirow{3}{*}{ Good } & Mean & 3.6950 & 3.6000 & 3.2320 & 3.7733 \\
\hline & $\mathrm{N}$ & 25 & 25 & 25 & 25 \\
\hline & Std. Deviation & .55326 & .45019 & .51455 & .58508 \\
\hline \multirow{3}{*}{ Very Good } & Mean & 3.7105 & 3.6667 & 3.4263 & 3.8246 \\
\hline & $\mathrm{N}$ & 19 & 19 & 19 & 19 \\
\hline & Std. Deviation & .56527 & .24568 & .45441 & .51960 \\
\hline \multirow{3}{*}{ Excellent } & Mean & 4.1000 & 3.8444 & 3.5600 & 4.2833 \\
\hline & $\mathrm{N}$ & 10 & 10 & 10 & 10 \\
\hline & Std. Deviation & .41583 & 46907 & .49710 & .43780 \\
\hline \multirow{3}{*}{ Total } & Mean & 3.6109 & 3.5639 & 3.3063 & 3.7354 \\
\hline & $\mathrm{N}$ & 80 & 80 & 80 & 80 \\
\hline & Std. Deviation & .62039 & .50587 & .53471 & .659 61 \\
\hline
\end{tabular}


Table 3 shows that emotional intelligence has a positive effect on students' achievement levels. The highest their score reported in the achievement test, the highest their level in emotional intelligence. Excellent, very good, and good students reported a higher level of using emotional intelligence subscales, more than failures or students with grade fair.

The following statistical analysis of ANOVA was conducted, to detect significant differences between the emotional intelligence subscales, in relation to academic success in learning English, as illustrated in Table 4.

Table 4. Emotional Intelligence Subscales in Relation to Academic Success in Learning English

\begin{tabular}{|c|c|c|c|c|c|c|}
\hline \multicolumn{7}{|c|}{ ANOVA } \\
\hline & & $\begin{array}{l}\text { Sum of } \\
\text { Squares }\end{array}$ & $d f$ & $\begin{array}{l}\text { Mean } \\
\text { Square }\end{array}$ & $F$ & Sig. \\
\hline \multirow{3}{*}{ Others } & Between Groups & 5.793 & 4 & 1.448 & 4.413 & .003 \\
\hline & Within Groups & 24.613 & 75 & .328 & & \\
\hline & Total & 30.406 & 79 & & & \\
\hline \multirow{3}{*}{ Self } & Between Groups & 2.277 & 4 & .569 & 2.379 & .059 \\
\hline & Within Groups & 17.940 & 75 & .239 & & \\
\hline & Total & 20.217 & 79 & & & \\
\hline \multirow{3}{*}{ Perception } & Between Groups & 1.393 & 4 & .348 & 1.233 & .304 \\
\hline & Within Groups & 21.193 & 75 & .283 & & \\
\hline & Total & 22.587 & 79 & & & \\
\hline \multirow{3}{*}{ Utilization } & Between Groups & 5.792 & 4 & 1.448 & 3.800 & .007 \\
\hline & Within Groups & 28.580 & 75 & .381 & & \\
\hline & Total & 34.372 & 79 & & & \\
\hline
\end{tabular}

Table 4 shows that there were significant differences in the use of emotional intelligence, with regard to achievement level. Students reported the influence of achievement level on the use of two subscales, "Managing others emotions" and "Utilization of emotion". Excellent, very good, and good students reported a higher level of using the subscales of "Managing others emotion" and "Utilization of emotion", more than failures or students with grade fair.

\section{Discussion}

Concerning the emotional intelligence level of Saudi EFL students, the findings of the present study revealed a high level of overall emotional intelligence of Saudi EFL undergraduate students. This result confirmed the results of Al-Shakifi's (2015) study which showed that Saudi undergraduate students had a high level of emotional intelligence. This suggests that Saudi EFL undergraduate students are able to control and regulate their own emotions, and that of others, when learning English. They are masters at utilizing and managing their emotions. They also have the ability to sense the emotional needs of others. They could manage their emotions to create positive social interactions and do not allow their actions to be emotion-driven.

At the category level, the results also indicated that Saudi EFL undergraduate students reported their high ability in the utilization of their emotions, followed by management of others' emotions, and management of self-emotions. Both received nearly the same level. Finally, students reported a lower level in perception of emotion. In other words, students showed that they have the ability to utilize their emotions most, to guide their own thoughts and actions, and to facilitate different types of learning, thinking and problem-solving. They had the ability to regulate emotions in themselves and others. They could adapt to the immediate surroundings. They could control even negative emotions to achieve their intended goals. The least used category was the perception of emotions. Students showed that they are moderate in identifying their own emotions. Besides, they could not detect emotions in voices, pictures, and faces highly.

In response to the second question, that investigated the relationship between emotional intelligence and achievement level, the findings indicated that emotional intelligence is an important factor that contributes to academic success in studying the English language. Successful Saudi EFL students reported higher levels of emotional intelligence than those who were less successful. This result was supported by earlier findings reported by Newsome, Day, \& Catano, 2000; Al-Asmari, 2014; and Sahinidi, Kallivokas, Antonatou, and Sdrolias, 2016. However, the findings of the present study contradicted the studies of Al-Ghamdi, 2014 and Sahinidis, Kallivokas, Antonatou, and Sdrolias, 2016. 


\section{Conclusion}

Saudi EFL students are able to utilize their emotions well in order to make good decisions; they could also manage their own emotions and that of others; finally, they had a medium perception of their emotions, as they do not know enough what their feelings are. The results of the present study also revealed that being emotionally intelligent helps in excelling in academic achievement. In other words, emotionally intelligent students usually succeed in their academic performance. This needs educational practitioners, academic policymakers, and teachers, to take emotional intelligence issues seriously, and to pay more attention to the emotions of their students. They should consider the emotional intelligence level in the classroom to assist their students in employing their full capacity in learning. Thus, it is important to incorporate emotional intelligence in university programms, as the systematic fostering of emotional intelligence could lead to successful academic performance.

Further research should approach the interaction of students' and teachers' emotional intelligence. It might also investigate further the effect of emotional intelligence on working under pressure. It could as well focus on identifying the emotional intelligence that is associated with societies and cultures.

\section{Acknowledgment}

I would like to express my sincere thanks to the respondents of the questionnaire and achievement test; I am also grateful to my editors for their useful comments and feedback.

\section{References}

Al-Asmari, A. (2014). Emotional intelligence and academic achievement: A comparative, gender based-study of undergraduate English language learners in Saudi Arabia. Journal of Education and Practice, 5(6), 178-190.

Al-Ghamdi, F. (2014). The role of trait emotional intelligence in individual performance: A descriptive study in Albaha University, Saudi Arabia. Journal of Service Science and Management, 7, 361-367. https://doi.org/10.4236/jssm.2014.75033.

Al-Shakifi, M., A. (2015). Mind habits and emotional intelligence and relationship with academic achievement among students at Al-Qanfada University College-The Kingdom of Saudi Arabia. The International Journal for Talent Development, 6(2), 33-59.

Alston, B. (2009). An examination of the relationship between emotional intelligence and leadership practices. (Unpublished doctoral dissertation). Nova Southeastern University, Florida.

Bar-On, R. (2006). The Bar-On model of emotional-social intelligence (ESI). Psicothema, 18, 13-25.

Bar-On, R. \& Parker, J. D. (Eds.). (2000). The handbook of emotional intelligence theory, development, assessment, application at home, school and in the workplace. San Francisco: Jossey-Bass/Pfieffer.

Cherniss, C. (2010). Emotional intelligence: Toward a clarification of a concept. Industrial and Organizational Psychology, 3, 110-126, https://doi.org/10.1111/j.1754-9434.2010.01231.x

Ciarrochi, J., Chan, A. Y. C. \& Caputi, P. (2000). A critical evaluation of the emotional intelligence concept. Personality and individual differences, 28(3), 1477-1490. https://doi.org/10.1016/S0191-8869(99)00119-1

Dacre Pool, L. \& Qualter, P. (2012). Improving emotional intelligence and emotional self-efficacy through a teaching intervention for university students. Learning and Individual Differences, 22(3), 306-312. http://dx.doi.org/10.1016/j.lindif.2012.01.010

Elhaj, N. (2015). The relationship between emotional intelligence and English language achievements among private secondary schools'students at Khartoum locality. The Ahfad Journal, 32(1), 15-29.

Elias, M., Arnold, H. \& Hussey, C. (2003). EQ+IQ+Best leadership practices for caring and successful school. CA: Thousand Oaks.

Imai, Y. (2010). Emotions in SLA: New insights from collaborative learning for an EFL classroom.. Modern Language Journal, 94(2), 278-292. http://doi.org/cqwt6x

Fahim, M. \& Pishghadam, R. (2007). On the role of emotional, psychometric, and verbal intelligences in the academic achievement of university students majoring in English language. Asian EFL Journal, 9, 240-253.

Gleman, D. (1998). Working with emotional intelligence. New York: Bantam.

Goleman, D. (1995). Emotional intelligence: Why it can matter more than IQ. New York: Bantam Books 
Goleman, D. (2001). Emotional intelligence: Issues in paradigm building. In C. Cherners \& D. Goleman (Eds.), The Emotionality intelligent workplace (pp. 13-26). San Francisco: Jossey-Bass.

Kashani, L., Azimi, L. \& Varziri, S. (2012). Relationship between emotional intelligence and educational achievement. Procedia Social and Behavioral Sciences, 69, 1270-1275. https://doi.org/10.1016/j.sbspro.2012.12.061

Kremenitzer, J. P. \& Miller, R. (2008). Are you a highly qualified, emotionally intelligent early childhood educator? Young Children, 63(4), 106-112.

Low, G. R., Lomax, A., Jackson, M. \& Nelson, D. (2004). Emotional intelligence: A new student development model. Paper presented at the 2004 National Conference of the American College Personnel Association, Philadelphia, $\begin{array}{lllll}\text { Pennsylvania. } & \text { Retrieved } & \text { November } & 29, & \text { 2009, }\end{array}$ https://pdfs.semanticscholar.org/48be/fc9180883782e590fb0e0f28ffb0c0395402.pdf

Mayer, J. D., Caruse, D. R. \& Salovey, P. (1999). Emotional intelligence meets traditional standards for an intelligence. Intelligence, 27, 267-298. http://dx.doi.org/10.1016/S0160-2896(99)00016-1

Mayer, J. D., Salovery, P. \& Caruso, D. R. (2000) Competing models of emotional intelligence. in R. J. Sternberg (Ed.), Handbook of human intelligence (PP. 396-420). New York: Cambridge University Press.

Mayer, J. D., Salovey, P. \& Caruso, D. (2000). Models of emotional intelligence. In R. J. Sternberg (Ed,), The handbook of intelligence (PP. 396-420). Nework: Cambridge University Press.

Mayer, J. D., Salovey, P. \& Caruso, D. (2004). Emotional intelligence: Theory, findings, and implication. Psychological Inquiry, 15(3), 197-215.

Mehta, S. \& Singh, N. (2013). A review paper on emotional intelligence: Models and relationship with other constructs. International Journal of Management \& Information Technology, 4(3), 342-352. https://doi.org/10.24297/ijmit.v4i3.772

Motallebzadeh, K. (2009). The relationship between the emotional intelligence of Iranian EFL learners and their reading comprehension and structural ability. Journal of Teaching English as a Foreign Language and Literature, 1(4), 39-55.

Oz, H. (2015). Emotional intelligence as a predictor of L2 communication. Procedia-Social and Behavioral Sciences, 186, 424-430. https://doi.org/10.1016/j.sbspro.2015.04.117

Petrides, K. V., Frederickson, N. \& Furnham, A. (2003). The role of trait emotional intelligence in academic performance and deviant behavior at school. Personality and Individual Differences, 36, 277-293. https://doi.org/10.1016/S0191-8869(03)00084-9

Qualter, P., Whiteley, H., Morely, A. \& Dudiac, H. (2009). The role of emotional intelligence in the decision to persist with academic studies in high education. Research in Post-Compulsory Education, 14(3), 219-231. https://doi.org/10.1080/13596740903139255

Sahinidis, A., Kallivokas, D., Markantonatou, A. \& Sdvolias, L. (2016). Emotional intelligence effects on academic performance. An empirical study of university students, Tourism Research Institute, 15(1), 151-162.

Saklofske, D. H., Austin, E. \& Minski, P. S. (2003). Factor structure and validity of a trait emotional intelligence measure. Personality and Individual Differences, 34, 707-721.

Salovery, P. \& Mayer, J. D. (1990). Emotional intelligence. Imagination, cognition, and Personality, 9, 185-211.

Schutte, N. S., Malouff, J. M. \& Bhullar, N. (2009). The Assessing emotions scale in C. Stough, D. H. Saklofske \& J. D. A. Parker (Eds.), The Springer Series on human exceptionality. Assessing emotional intelligence: Theory, research, and application (pp. 119-134), New York, NY, US:Springer Science+Business Media. http://dx.doi.org/10.1007/978-0-387-88370-0_7

Shuib, N., Ishak, N., Amat, S. \& Ahmad, I. (2018). Emotional intelligence and academic achievement of primary school students in Malaysia. Social Science and Humanities Journal, 2(9), 594-601.

Wicks, J., Nakisher, S. \& Grimm, L. (2018). Emotional intelligence (EI). Salem Press Encyclopedia of Health. Retrieved from http://search.ebscohost.com.sdl.idm.oclc.org/login.aspx?direct=true\&db=ers\&AN=93871908\&site=eds-live

Zeidner, M., Roberts, R. D. \& Matthew, G. (2002). Can emotional intelligence be schooled? A Critical Review. Educational Psychology, 37(4), 215-231. https://doi.org/10.1207/S15326985EP3704_2 